\title{
WASHINGTON LUÍS E A QUESTÃO SOCIAL
}

\author{
Octávio Bueno Magano \\ Professor Titular de Direito do Trabalho da \\ Faculdade de Direito da Universidade de São Paulo
}

\begin{abstract}
Resumo:
Confrontado o governo de Washington Luis com múltiplos fatores geradores de instabilidade, era preciso manter-se atilado, firme e sereno, como sempre se manteve. Era mister, sobretudo, que se mostrasse capaz de separar o joio do trigo, isto é, que tivesse perspicácia para compreender, como o fez, que a "questão social" se apresenta com múltiplas dimensões e que, em conseqüência, cumpria-lhe distinguir movimentações sociais genuinas, de caráter democrático, das de feição demagógica, destinadas à propagação de ideologias extremistas ou à promoção de interesses partidários, grupais, ou mesmo de indivíduos.

As realizações de Washington Luis, na área social, não foram poucas. Merecem realce as seguintes: criação dos tribunais rurais, pela Lei estadual n. 1.869, de 10 de outubro de 1922; edição do Código de Menores, pelo Decreto n. 17.943-A, de 12 de outubro de 1927, reformulação do Conselho Nacional do Trabalho, pelo Decreto n. 18.074, de 19.01.1928.
\end{abstract}

\begin{abstract}
:
Since the government of Washington Luis was confronted with multiple factors which generate instability, it was incumbent for him to be prepared, firm and serene as he was always reknown to be. It was necessary above all, that he be able to identify the main problems, that is the ability to understand, like he did, that the "social question" has multiple dimensions which imposes distinction between genuine social movements with democratic character and the demagogic ones, destined to spread extremist ideologies or else, of interest only of few, of groups, or even. of individuals.

Washington Luis's accomplishments, in the social field, were not few. The most outstanding ones being: criation of rural Courts, through State Law n. 1.869, published on October 10, 1912; edition of the Statute for Minors through Decree n. 17.943-A, dated October 12, 1927; reformulation of the National Labor Council, through Decree n. 18.074, dated January 1, 1928.
\end{abstract}

\section{Traços pessoais}

Washington Luís Pereira de Souza nasceu em Macaé, Rio de Janeiro, no dia 26 de outubro de 1869. Em 1884, iniciava estudos secundários no Colégio Pedro II, no Rio de Janeiro. Em 1888, deslocava-se para São Paulo, a fim de se inscrever no curso preparatório de ingresso na Faculdade de Direito. Cursou-a de 
1889 a 1891. Em 1892, tornou-se promotor público da Comarca de Barra Mansa, no Rio de Janeiro, mas, logo a seguir, transferiu-se para Batatais, no Estado de São Paulo, a convite de Celidônio Reis Júnior, de quem se tornou sócio, num escritório de advocacia. Em 1897, elegeu-se vereador e presidente da Câmara Municipal do referido Município. Em 1904 inseriu-se no cenário político, como deputado estadual, tomando parte da revisão constitucional de 1905. Em 1906, foi nomeado para a Secretaria da Justiça, onde permaneceu até 1912, sob os governos de Jorge Tibiriçá e Albuquerque Lins. Depois de breve retorno à assembléia estadual de deputados, em 30 de outubro de 1913, foi guindado ao posto de Prefeito de São Paulo, condição conservada em virtude de reeleição até agosto de 1919. O posto subseqüente foi o de Governador do Estado de São Paulo, no quatriênio 1920-1924. A sua carreira política culminou com o exercício da Presidência da República, no período entre 1926 a 1930, posto do qual foi destituído poucos dias do término de seu mandato, em virtude da Revolução promovida pela chamada Aliança Liberal.

\section{Retificação}

A memória de Washington Luís Pereira de Souza tem sido denegrida através do refrão de que, para ele, a questão social traduzir-se-ia em caso de política. A acusação não é verdadeira, tendo sido veementemente repudiada pela vítima de seus efeitos, em carta dirigida ao grande mestre Evaristo de Moraes Filho, nestes termos: "Eu jamais disse, ou escrevi, e jamais poderia ter dito, que a questão social era uma questão de politica, frase que o mais bisonho político, mesmo em nossa terra, não ousaria empregar." Nada obstante, o enganoso estribilho, inventado pelos líderes da Aliança Liberal, até hoje ressoa. Getúlio Vargas tornou-se um dos pregoeiros desse vitupério, escrevendo: "Não exageramos, recordando que, para a mentalidade predominante no regime passado, o problema operário no Brasil, era simples questão de política."2

Todo o alarido, em torno desse assunto, originou-se do tópico abaixo reproduzido, constante da plataforma de governo apresentada, em 25 de janeiro de 1920, no Teatro Municipal: "Tratando das indústrias, falando sobre o capital, não

1. Moraes Filho, Evaristo de, Washington Luis e a Questão Social, in Rev. Ltr, v. 52, n. 9 . setembro/88, p. 1.043 .

2. A Nova Politica do Brasil l - Da Aliança Liberal às realizações do $1^{\circ}$ ano de Governo 19301931, Rio de Janeiro, José Olympio, s.d., p. 344 
poderia eu silenciar o operário. A legislação operária, porém, por entender com a propriedade e com a liberdade de trabalho, por pertencer à parte substantiva do direito, é matéria sobre a qual só a União pode legalmente dispor; mas, no momento actual, ninguém póde se desinteressar de tal questão. Ainda por muitos annos, e eu vos falo para o minuto de um quatrienio, entre nós, em São Paulo pelo menos, a agitação operária é uma questão que interessa mais à ordem pública do que à ordem social; representa ella o estado de espirito de alguns operários, mas não o estado de uma sociedade."

Tomada isoladamente a frase, "a agitação operária é uma questão que interessa mais à ordem pública do que à ordem social ", poderia talvez gerar o entendimento de que o presidente Washington Luís considerasse a questão social caso de polícia. Mas lida a frase no contexto em que se inseriu, tal conclusão se mostra maliciosa. Para que se tenha certeza disso, basta para o início do período: "Tratando-se de indústrias, falando sobre o capital, não poderia eu silenciar o operário"- E mais adiante: “...ninguém pode se desinteressar de tal questão."

Vale dizer que a leitura não-deturpada do período em que se encaixaram as referências à ordem social e à ordem pública não deixa qualquer dúvida sobre interesse de Washington Luís pela questão social. $O$ que queria repudiar era a sua manipulação demagógica.

De qualquer maneira, uma pessoa, um político, um estadista não pode, de maneira alguma, ser julgado apenas pelo teor de frase lançada ao ar ou no papel. É mister, ao contrário, considerar-se o conjunto de suas realizações e atividades.

Como é notório, o governo de Washington Luís foi pleno de realizações, em todas as áreas da administração.

Há de se assinalar, em primeiro lugar, a enorme expansão dada por ele à geografia do Brasil, com a doação da diretriz de que "governar é abrir estradas", o que, no dizer de Carlos Maul significa "estaca zero de qualquer empreendimento humano, no rumo das conquistas do bem-estar social..."

Cumpre sublinhar, a seguir, a restauração da liberdade de imprensa, pela suspensão do estado de sítio. Em terceiro lugar, é mister dar ênfase às medidas

3. Egas, Eugenio, Quatriênio Presidencial do Dr. Washington Luis 1920/1924, São Paulo, s.c.e., 1924 , p. 96.

4. Quem abre estrada constróe civilização, in Washington Luís (visto pelos Contemporâneos do Primeiro Centenário de seu Nascimento), São Paulo, Instituto Histórico e Geográfico de São Paulo, 1969, p. 253. 
de estímulo à economia, responsáveis pela duplicação da produção do café, no período entre 1925 e 1929. Não pode ficar sem menção a reforma financeira, compreendendo reorganização das finanças, equilíbrio orçamentário, aumento das reservas de ouro. E não se há de omitir tampouco a remodelação urbana da cidade do Rio de Janeiro, sob a administração do paulista Antônio Prado Jr.

$\mathrm{Na}$ área do ensino, cumpre realçar que só no seu governo deu-se execução ao preceito constitucional da obrigatoriedade do ensino primário. ${ }^{5}$

$\mathrm{Na}$ área política, preocupou-se com o problema sucessório, indicando para o substituir Júlio Prestes, paulista ilustre. A resistência à sua indicação resultou principalmente de ressentimentos do mineiro Antônio Carlos, que se julgou preterido e foi, por isso, procurar aliados no Rio Grande do Sul.

$\mathrm{Na}$ esfera específica do social, as realizações de Washington Luís não foram poucas. Antes, porém, de as analisar é mister estabelecer, com clareza, o significado da questão social.

\section{Questão social}

Como lembra Sampaio Dória, "a questão social é de todos os lugares e de todos tempos..."

Tornou-se, porém, mais aguda a partir da Revolução Industrial iniciada em meado do século XVIII e apresenta-se hoje com várias dimensões: a econômia, a religiosa, a política, a moral e a jurídica.

\section{a. Dimensão econômica}

Do ponto de vista econômico, pode-se afirmar que a questão social surgiu com o advento da Revolução Industrial, em meados do século XVIII, e que esquematicamente consistiu no aperfeiçoamento da técnica de produzir, proporcionado pelas invenções, notadamente a da máquina a vapor; na substituição do trabalho manual, com utilização de instrumentos próprios, pelo trabalho com máquinas alheias; na concentração dos trabalhadores nas fábricas e na implantação destas em centros industriais; na divisão do trabalho, cada trabalhador se incumbindo de uma determinada operação produtiva.

5. Barreto, A. Romano, Washington Luis e a Reforma do Ensino, in idem, p. 75.

6. A Questão Social, São Paulo, Monteiro Lobato, 1922, p. 5. 
b. Dimensão religiosa

Sob o aspecto religioso, a questão social tomou a significação de maior envolvimento da Igreja na vida temporal, cujo marco inicial é a publicação da Encíclica Rerum Novarum, pelo Papa Leão XIII, em 1891. ${ }^{7}$ Nesse documento, assim se enunciou a questão social: “...os progressos incessantes da indústria, os novos caminhos em que entraram as artes, a alteração das relações entre operários $e$ patrões, a afluência da riqueza nas mãos desse pequeno número ao lado da indigência da multidão, a opinião enfim mais avantajada que os operários formam de si mesmos e a sua união mais compacta, tudo isso, sem falar da corrupção dos costumes, deu em resultado final um terrivel conflito."

\section{c. Dimensão política}

Sob esse ângulo, a questão social significou o florescimento de ideologias, quer dizer, de teorias voltadas para a ação como é o caso do comunismo, das várias espécies de socialismo, do anarquismo, do facismo, do nazismo, do corporativismo, etc. Todos esses ismos, surgidos no correr do século XIX e nas primeiras décadas do século $\mathrm{XX}$, se formaram como teorias, mas também como programas quase sempre de natureza demagógica, desenvolvidos por indivíduos ou grupos para a conquista do poder.

\section{d. Dimensão moral}

A questão social fez com que surgisse nova concepção a respeito da pobreza, que deixou de ser considerada como resultado da preguiça e da incompetência para ser explicada como conseqüência de defeituosa organização da sociedade. Tornou-se, assim, para muitos, problemas de natureza exclusivamente econômica. Não porém para a Igreja, consoante se infere desta passagem da Encíclica Quadragésimo Anno, de Pio XI: “...ainda que a economia e a moral se regulem cada uma no seu âmbito, por princípios é erro julgar a ordem econômica $e$ a moral tão encontradas e alheias entre si, que de modo nenhum aqueda dependa desta."

7. Seguiram-se as Encíclicas Quadragesimo Anno e Divini Redemptoris, de Pio XI; Master et Magistra, de João XXIII; Populorum Progressio, de Paulo VI. 


\section{e. Dimensão jurídica}

Sob o aspecto em foco, assistiu-se ao fenômeno da socialização do Direito, significando a prevalência dos interesses sociais sobre os individuais. Presenciou-se também o fenômeno do alargamento das fronteiras do Direito Público não-só em virtude da expansão do conceito de serviço público, senão também por causa da amplificação da ordem pública na área do Direito Privado. Chegou esta a tal ponto que gerou dúvidas sobre a própria viabilidade da distinção entre Direito Público e Direito Privado. ${ }^{8}$ Afora parte a Inglaterra, os Estados Unidos da América do Norte e outros países pertencentes ao sistema da Common Law, onde a questão social foi enfrentada exclusivamente pela legislação ordinária, nos demais países, o seu reconhecimento deu origem ao constitucionalismo social, consistente na transposição para os respectivos textos constitucionais de princípios tendentes a permitir a direção da economia pelo Estado e assegurar a proteção e a melhoria da condição social do trabalhador. Consoante Mariano Tissembau, o temário do constitucionalismo social se desdobra nos seguintes tópicos: "10) segurança individual; $2^{\circ}$ ) trabalho; $3^{\circ}$ ) segurança social; $4^{\circ}$ ) atividade econômica; $5^{\circ}$ ) saúde e $6^{\circ}$ ) justiça social." ${ }^{\prime \prime}$ As duas primeiras Constituições em que se agasalhou o referido temário foram a mexicana, de 1917 e a de Weimar, de 1919.

Por último, é preciso assinalar que a questão social deu ensejo ao nascimento de dois novos ramos do Direito: o Direito Econômico, caracterizado como o Direito do novo Estado industrial ${ }^{10}$ e o Direito do Trabalho.

\section{Evolução da questão social}

A partir da Revolução Industrial a questão social passou pelas fases a seguir descritas:

8. Radbruch, Gustav, Introduzione alla Scienza del Diritto, Torino, Giappichelli, 1958, p. 201.

9. La constitucionalización del Derecho del Trabajo, su Codificación, Fuentes e Interpretatión, Buenos Aires, La Ley, 1971, tomo I, p. 223.

10. Farjat, Gérard, Droit Économique, Paris, Presses Universitaires, 1971, p. 10. Sobre o objeto desse Direito vide Vidigal, Geraldo de Camargo, Objeto do Direito Econômico, São Paulo, s.c.e., 1976 
a. Fase do apogeu do Liberalismo

Esta fase se estende desde a Revolução Francesa, em 1789, que a consagrou politicamente, até 1848 , quando os seus pressupostos foram contestados pela revolução popular ocorrida, no mesmo ano, na França, e pela publicação do Manifesto Comunista, de Marx e Engels. As características fundamentais desse período são a da projeção de uma sociedade individualista, sem corpos intermediários e a do não-intervencionismo estatal, as quais foram realçadas pela Lei Le Chapelier, de 1791, que proibiu na França o funcionamento das corporações: pelos Combinations Acts, de 1799 e 1800, na Inglaterra, que converteram em conspiração a reunião de trabalhadores; pelo Código Penal francês, de 1810, que considerou crime a coalização de trabalhadores; pela Poor Law inglesa, de 1834, que eliminou a concessão de auxílio aos pobres, fora das Poor Houses.

Nesse quadro, não havia evidentemente clima propício para o desenvolvimento do Direito do Trabalho. Não obstante, algumas leis trabalhistas foram editadas. Na Inglaterra, merecem realce o Heath and Morals of Apprentices $A c t$, de 1802, que limitou a doze horas o trabalho do menor de doze anos e o Factory $A c t, 1833$, que instituiu a inspeção do trabalho e estabeleceu limitações à jornada de trabalho. É de se assinalar, ainda, a renovação em 1824 e 1825, dos Combinations Acts; a reforma eleitoral aprovada em 1832, permitindo ampla participação do eleitorado na escolha de representantes junto ao Parlamento e a criação, sob inspiração de Robert Owen, da Grand National Consolidated Trades Union. ${ }^{11} \mathrm{Na}$ França, deve ser referida a lei de 22 de março de 1841, que proibiu o trabalho de menores de oito anos e limitou a doze horas diárias o trabalho dos menores entre oito e doze anos.

b. Fase de contestação do Liberalismo

Esta fase se estende desde 1848, com a Revolução Francesa do mesmo ano e a publicação do Manifesto Comunista, de Marx e Engels, até o advento da Primeira Grande Guerra, em 1914. 
A Revolução de 1848 constituiu o primeiro ensaio de reformas sociais que bem se acentuaram com a instituição da Comissão de Luxemburgo ${ }^{12}$ e a criação das Oficinas Nacionais. ${ }^{13}$ O Manifesto Comunista foi um desafio aberto ao liberalismo e à hegemonia burguesa.

Os dois fatos em causa funcionaram como poderosos sinais de alerta no sentindo de que o liberalismo, para se preservar, deveria começar a fazer concessões aos trabalhadores. E assim inaugurou-se a fase de crescente intervencionismo estatal e de vez mais amplo reconhecimento dos grupos profissionais, merecendo realce, na Inglaterra, os Factory Acts, de 1864, 1867 e 1901; a nova reforma eleitoral de 1867; a criação do Trade Union Congress, em 1868; a Trade Union Act, de 1871, tornando lícita a atuação dos sindicatos; a do Conspiracy and Protection of Property Act, de 1875, autorizando o picketing pacífico; a do Trade Dispute Act, de 1906, concedendo imunidade aos sindicatos e aos seus diretores, por atos praticados em seu nome, causadores de danos a terceiros; a do Trade Union Act, de 1913, autorizando expressamente os sindicatos a se utilizarem de seus bens para fins políticos; a lei de acidentes do trabalho em 1897; a da lei da jornada de oito horas em 1908; a da legislação sobre salário mínimo, seguro-saúde, seguro-desemprego, aposentadoria por velhice, do período entre 1909 a 1911. Na França, é mister sublinhar a Lei de 25 de março de 1864, que aboliu o delito de coalização; a Lei de 19 de maio de 1874, que instituiu a inspeção do trabalho; a Lei Waldeck-Rousseau, de 21 de março de 1884, que assegurou a liberdade sindical; a Lei de 9 de abril de 1898, sobre acidentes do trabalho, a Lei de 13 de julho de 1906, sobre repouso hebdomadário. Na Alemanha, não podem ficar sem menção as leis respectivamente de 1883,1884 e 1889 que, de modo vanguardeiro, instituíram respectivamente os seguros contra enfermidade, acidentes do trabalho, invalidez e velhice.

c. Fase do Intervencionismo

Esta fase se inicia com o término da Primeira Grande Guerra, assinalando o reconhecimento universal do intervencionismo do Estado, para a

12. Comissão composta de dez trabalhadores empregadores, presidida por Louis Blanc e encarregada de assuntos do trabalho.

13. As oficinas nacionais foram organizadas para dar ocupação a todos os que se encontrassem sem trabalho. 
solução da questão social. Os fatos que melhor a caracterizam são os seguintes: a. criação da Organização Internacional do Trabalho, conforme previsão da parte XIII, do Tratado de Versalhes, cuja atividade deveria visar à realização dos seguintes princípios: o de que o trabalho não pode ser tido como mercadoria; o do direito de associação; o do salário mínimo; o da isonomia salarial, sem distinção de sexo; o do descanso semanal; o da jornada de oito horas; o da não-discriminação contra trabalhadores estrangeiros; o da inspeção do trabalho; b. o apoio da Igreja ao mesmo intervencionismo, de acordo com as diretrizes traçadas na Encíclica Rerum Novarum, do Papa Leão XIII; c. a implantação do comunismo, na Rússia, em 1917 e as experiências nacionalistas e corporativistas da Itália, Alemanha, Áustria, Espanha e Portugal; d. o constitucionalismo social, iniciado com as Constituições do México, de 1917 e de Weimar, de 1919; e. o advento do New Deal, nos Estados Unidos, depois da crise econômica de 1929 e a conseqüente promulgação do Norris La Guardia Act, de 1932 e do Wegner Act, de 1935.

\section{Configurações concretas da questão social}

Antes de passar ao exame da questão social no Brasil, convém considerar suas principais configurações em outros países, após o término da Primeira Grande Guerra, período que coincide com a emergência política de Washington Luís, entre 1920 e 1930.

Tão envolvente fora a Guerra de 1914-18; tão devastadora de vida e bens que, após o seu término, ansiava-se por nova ordem para o mundo. A concepção liberal passou a ser contrastada por vários ismos, o socialismo, o comunismo, o fascismo, o corporativismo, o nazismo, etc.

Mas esse entrechoque de concepções projetou-se com características próprias conforme o país que se considere.

\section{a. França}

Em França, é preciso registrar, antes de mais nada, a cisão entre socialistas e comunistas, ocorrida em 1920, no Congresso de Tours e, em 1922, a cisão entre a CGT e a CGTU, de orientação comunista. Mas o fato mais significativo foi a formação do Cartel des Gauches, quando das eleições de maio de 1924. Aglomeraram-se, então, os socialistas (SFIU), os radicais socialistas, os republicanos socialistas e a esquerda radical, sob a direção de Edouard Herriot. 
Mas, para bem se avaliar a instabilidade dessa fase histórica, cumpre assinalar que, já em julho de 1926, forma-se governo de união nacional, tendo a frente R. Poincaré, de grande respeitabilidade e que foi capaz de restaurar a solidez financeira do país.

b. Itália

A Itália saiu da guerra em situação anárquica, que muito favoreceu o advento do fascismo. Em outubro de 1922, deu-se a marcha de Mussolini sobre Roma e a sua investidura no poder. Eliminada a posição, inclusive com o assassinato do chefe socialista, Matteotti, e a liquidação dos sindicatos independentes, em proveito dos de índole fascista, em 1927, promulgava-se a Carta de Trabalho, em que se traçaram as características fundamentais do fascismo.

\section{c. Alemanha}

Na Alemanha, há de se assinalar, inicialmente, o surgimento da Constituição de Weimar, de 1919, precursora do chamado constitucionalismo social. Mas o regime vivia ameaçado pelas repercussões econômicas e sociais da guerra e pelas dificuldades no intercâmbio com outros países, notadamente após a ocupação do Vale do Ruhr, ocorrida em 1923. Tudo isso era causa de grande instabilidade, o que explica a tentativa falha de golpe de estado levada a efeito, por Hitler, em Munique, em novembro de 1923.

\section{d. Inglaterra}

Terminada a Guerra de 1914-18, a Inglaterra teve de se defrontar com nova realidade determinada pela concorrência de países e economicamente rivais, sobretudo os Estados Unidos. A sua economia fundada até então sobre o carvão fica ameaçada pelo emprego crescente do petróleo e da eletricidade. Resulta daí a grave crise econômica e social, gerando desemprego para mais de 2 milhões e meio de trabalhadores e cadeia sucessiva de greves. Daí resultou, a seu turno, crise política ocasionadora da queda do governo conservador de Lloyd George, em 1922 e ascensão do governo trabalhista de Ramsay MacDonald, em 1924. Breve interlúdio conservador é seguido de nova vitória trabalhista, com a recondução de MacDonald ao poder, em 1929. 
e. $E U A$

Depois do período de grande prosperidade dos EUA, entre 1919 e 1929, explicável em razão da diminuição da concorrência dos países europeus, debilitados pelos efeitos da Primeira Grande Guerra Mundial, surge o colapso da Bolsa de Valores americana do dia 22 de outubro de 1929, gerador de crise mundial de proporções catastróficas, que só nos EUA, levou ao desemprego mais de 15 milhões de trabalhadores.

\section{f. Espanha}

$\mathrm{Na}$ Espanha, a situação política, já deteriorada, após o término da Primeira Grande Guerra Mundial, tornou-se extremamente tensa, com a criação da Central Nacional dos Trabalhadores (CNT) no Congresso de Sants, de 1918. A violência nos confrontos entre trabalhadores e empregadores, tanto quanto o impasse na solução da Guerra de Marrocos, serviram para justificar o golpe militar de Primo de Rivera, que governou ditatorialmente o país, de 1923 a 1927.

\section{g. Portugal}

Em Portugal, a partir de 1917, desencadeou-se período de grande turbulência ensejador do golpe militar de Sidônio Pais, que se apoderou do governo, fez-se eleger presidente da República e modificou ditatorialmente a Constituição, no sentido presidencialista. Acabou sendo ele assassinado em dezembro de 1918. Sucederam-se várias revoltas na país, até que, no dia 28 de maio de 1926, o general Gomes da Costa sublevou algumas tropas da guarnição de Braga, dirigiu-se ao Porto, sem qualquer resistência e continuou depois, à frente das tropas que se lhe foram agregando. Ao chegar a Lisboa dissolveu o Parlamento e implantou ditadura militar.

\section{Questão social no Brasil}

Como se depreende da exposição contida no tópico anterior, o quadro formado, após o término da Primeira Grande Guerra, foi o de um mundo convulsionado, o que não poderia deixar de ter reflexos no Brasil.

Além do influxo de novas ideologias e dos efeitos de crises econômicas, outro fato a se considerar, no estudo da questão social no Brasil, é o do crescimento fabril, ocorrido durante a conflagração mundial. 
O aspecto ideológico refletiu-se na fundação dos partidos socialista e comunista, respectivamente, em 1920 e 1922. A do primeiro deles havia sido precedida da organização do Grupo Clarté, constituido na França por intelectuais ex-combatentes, de cujo manifesto realça-se esta passagem: "É tempo de nos levantarmos nas nossas respectivas pátrias contra os fautores de guerras $e$ desordens. Intelectuais combatentes do mundo inteiro unamonos!" Esse manifesto teve grande repercussão no Brasil, provocando a fundação, em 1920, do Grupo Clarté brasileiro, inicialmente integrado por Nicanor Nascimento, Evaristo de Morais, Maurício de Lacerda, Pontes de Miranda, Everardo Dias e outros.

Seguindo diretriz paralela a do Grupo Clarté, alguns de seus principais organizadores resolveram fundar, também em 1920, o Partido Socialista, divulgando manifesto do qual merece relevo o tópico seguinte: "O Partido Socialista visa (...) nortear o operariado nas suas reivindicações e na defesa de seus ideais e pleitear a solução prática de todos os problemas que se relacionam com a remodelação da sociedade contemporânea, no ponto de vista econômico, moral intelectual, jurídico e político; estudar, sob seus diferentes aspectos, o trabalho nacional e os meios de melhorar as atuais condições de existências das classes salariadas; advogar a co-participação dos trabalhadores nos lucros das empresas industriais, comerciais e agrícolas; fundar universidades populares, bibliotecas e centros de conferências públicas; instituir serviço de assistência médicofarmacêutica e judiciária e outros que possam favorecer o avanço do movimento socialista brasileiro." 14

Em março de 1922, dava-se a fundação do Partido Comunista do Brasil, cuja palavra de ordem era a seguinte: "Organização... todos os trabalhadores para dentro dos sindicatos" Grande foi a influência desse partido não-só na organização de sindicatos de trabalhadores mas também na sublevação do Exército, sobretudo com a formação do chamado tenentismo e com o desencadeamento da célebre coluna Prestes, que disseminou a cizânia pelos sertões brasileiros, até recolher-se à Bolívia, em 1926.

A sublevação do Exército nutriu-se inicialmente da nomeação por parte de Epitácio Pessoa de dois civis para pastas militares: Pandiá Calógeras e Raul Soares. Depois veio a história das cartas em que se assacavam ofensas contra altas patentes do Exército, cuja autoria atribuiu-se maliciosamente a Arthur Bernardes, 
candidato oficial à sucessão de Epitácio Pessoa. Seguiu-se a rebelião do Forte de Copacabana, de 5 de julho de 1922.

As crises econômica resultantes da necessidade de redimensionamento das diversas economias nacionais, em relação ao mercado mundial, provocaram grande instabilidade nas finanças brasileiras, notadamente a crise da Bolsa de Valores americana, de 22 de outubro de 1929.

O crescimento fabril brasileiro resultou diretamente do desabastecimento do mercado mundial provocado pela Primeira Grande Guerra. Leva volumosa de imigrantes socialistas e anarquistas, oriunda principalmente da Itália, ao mesmo tempo que vinham para o Brasil, a fim de ocupar novos postos de trabalho, tornaram-se destacados partícipes de agitações sociais. Estas se exteriorizaram através de sucessivas e espraiadas greves principalmente em São Paulo, Rio de Janeiro, Salvador e Recife.

Confrontado o governo de Washington Luís com tantos fatores geradores de instabilidade, era preciso manter-se atilado, firme e sereno, como sempre se manteve. Era mister, sobretudo, que se mostrasse capaz de separar o joio do trigo, isto é, que tivesse perspicácia para compreender, como o fez, que a "questão social" se apresenta com múltiplas dimensões e que, em conseqüência, cumpria-lhe distinguir movimentações sociais genuínas, de caráter democrático, das de feição demagógica, destinadas à propagação de ideologias extremistas ou à promoção de interesses partidários, grupais, ou mesmo de indivíduos.

\section{Realizações na área social}

Como já antes solientado, as realizações de Washington Luís, na área social, não foram poucas. Merecem realce as seguintes: criação dos tribunais rurais, pela Lei estadual n. 1.869, de 10 de outubro de 1922; edição do Código de Menores, pelo Decreto n. 17.943-A, de 21 de outubro de 1927; reformulação do Conselho Nacional do Trabalho, pelo Decreto n. 18.074, de 19.1.1928; regulamentação do trabalho de artistas, pelo Decreto n. 5.492, de 16.7.1928; disciplina da situação jurídica dos índios, pelo Decreto n. 5.484, de 27 de junho de 1928; concessão de benefícios aos trabalhadores das empresas radiotelegráficas, pelo Decreto n. 5.485, de 30.6.1928; concessão de aposentadoria com vencimentos integrais a funcionários da União invalidados, quando a serviço da Nação, pelo Decreto n. 5.434, de 10 de janeiro de 1928 . 
Não vou aqui analisar todos os diplomas legislativos acima arrolados, o que estenderia em demasia o tamanho deste trabalho. Limitar-me-ei a considerar apenas os relativos às seguintes matérias: tribunais rurais; Código de Menores e disciplina jurídica dos índios.

\section{Tribunais rurais}

Deu-se a criação do tribunais rurais, consoante já salientado, pela Lei Estadual n. 1.869, de 10 de outubro de 1922. O objetivo por ela visado foi o de assegurar julgamento rápido, equitativo e pouco oneroso para os cofres públicos, das questões trabalhistas, surgidas no meio rural. $\mathrm{O}$ art. $2^{\circ}$ de referida lei, abaixo transcrito, dá clara idéia da estrutura dos tribunais em causa:

“o Tribunal rural se comporá do juiz de direito da comarca onde estiver situada a propriedade agrícola, $e$ de dois outros membros designados um pelo locador $e$ outro pelo locatário"

A determinação de que as próprias partes indicassem os juízes de sua confiança, aliviava o Poder Público do pesadíssimo ônus de manter Justiça do Trabalho com organização paritária.

E não há dúvida de que era a tais juízes que incumbia o julgamento da causa, como claramente se deduz do art. $5^{\circ}$, da lei em foco:

"...os dois membros do tribunal proferirão, se estiverem de acordo, a sua decisão, que será tomada por termo e homologada pelo Juiz de Direito."

A Intervenção do Juiz de Direito para efeitos decisórios só tinha lugar em caso de empate.

De acordo com isso, preceituava o art. $6^{\circ}$, da lei em análise:

"Havendo desacordo, tomado por termo os dois votos, decidirá o Juiz, no mesmo ato, fundamentando o julgamento."

Não se pense que a generalidade dos casos houvesse de redundar em impasse perante os dois juízes indicados pelas partes, porquanto a França possui 
sistema semelhante, constituído pelos conseils de Prud'Hommes e as causas ali apresentadas fluem normalmente.

Cada Conselho francês se desdobra em cinco seções: a da indústria, a do comércio, a de atividades diversas; a dos profissionais de carreira (cadres) e a da agricultura. Em cada seção, uma junta de conciliação composta de um conselheiro assalariado e de outro empregador; e, ao lado dela, uma junta de julgamento constituída de dois conselheiros assalariados e de outros dois empregadores.

Só em caso de empate, chama-se um magistrado profissional, que funcionará, então, como juge départiteur.

O modelo de Justiça Trabalhista, implantado por Washington Luís, como se vê, além de encontrar eco no Direito Comparado, tinha o mérito de ser rápido e não-oneroso para os cofres públicos. Podia funcionar com rapidez porque não havia limitação de número de árbitros a serem indicados pelas partes. E não era oneroso para os cofres públicos, porque a indicação dos árbitros constituía responsabilidade dos próprios litigantes.

Agora, quando se sabe que a Justiça do Trabalho defronta-se com um volume gigantesco de 1,8 milhão de processos, que dificilmente chegam a seu termo antes do decurso de cinco anos, talvez fosse o caso de se revogar a legislação vigente e se implantar, em nível nacional, o modelo de solução de litígios arquitetado por Washington Luís.

\section{Código de Menores}

Com a expedição do Decreto n. 17.943-A, de 12.10.1927, Washington Luís implantou o primeiro Código de Menores na América Latina.

Antecipando-se ao Estatuto da Crianção e do Adolescente, editado pela Lei n. 8.069, de 13.7.90, o referido Código concebia a criança e o adolescente como criaturas que deveriam receber tratamento prioritário da família, da comunidade, da sociedade em geral e do Poder Público.

Para tais efeitos, dava grande ênfase à proteção das crianças da primeira idade, aos menores abandonados, ao trabalho dos menores e aos abrigos de menores abandonados.

Crianças da primeira idade consideravam-se aquelas com menos de dois anos entregues a cuidados extrafamiliares e em relação às quais deveria exercerse rigorosa vigilância. 
Menores abandonados consideravam-se os de menos de 18 anos, sem habilitação certa nem meios de subsistência.

No que concerne ao trabalho, proibia-se a ocupação aos menores de 14 anos que não houvessem completado instrução primária e de todos os menores em serviços perigosos ou insalubres.

Para amparo dos menores abandonados, instituíram-se, sob supervisão do Juizado de Menores, abrigos destinados a recebê-los e onde deveriam exercer as seguintes atividades: exercícios de leitura, escrita e contas, lições de coisas e desenho, trabalhos manuais, ginástica e jogos desportivos.

10. Índios

Outro tópico importante na avaliação da política social de Washington Luís foi o dos índios. Ao regular a situação deles, através do Decreto n. 5.484, de 27 de junho de 1928, evitou radicalismos. Nem adotou o critério da forçada integração na cultura nacional nem perfilhou a diretriz de que devessem ser estimulados a desenvolver cultura própria. O seu desígnio foi o de proteger. Para esse efeito, dividiu-se em quatro categorias: a dos nômades; a dos arranchados; a dos integrados em povoações próprias e a dos inseridos em centros agrícolas.

Só dos últimos exigiu que se submetessem à disciplina da ordem civil, como obrigatoriedade de registro de nascimento, de celebração de casamento, de disposição de bens, etc.

No que concerne à ordem penal, ficaram os índios das três primeiras categorias equiparados aos menores, quer dizer, foram colocados na categoria de pessoas penalmente inimputáveis.

Por último, no que toca à posse de terras, dispôs expressamente o decreto baixado por Washington Luís, sobre a obrigatoriedade geral de a respeitar, esclarecendo caber também aos índios o uso e o gozo das riquezas naturais encontradas nas mesmas terras.

\section{Conclusão}

Como se depreende do exposto, grande foi a preocupação de Washington Luís com a questão social. Só que não se rendeu à onda demagógica que queria resolvê-la com soluções radicais de caráter populista ou corporativista. 
Já o seu sucessor Getúlio Vargas, optou por resolvê-la de acordo com o modelo do corporativismo italiano, impregnado do intuito demagógico de exaltação do Chefe de Governo.

Aliás, logo depois de instalado no poder, um dos primeiros atos praticados pelo referido político foi a expedição do Decreto n. 19.398, de 11 de novembro de 1930, em cujo art. $1^{\circ}$ lia-se o seguinte: "O Governo Provisório exercerá discricionariamente, em toda sua plenitude, as funções e atribuições nãosó do Poder Executivo, como também do Poder Legislativo..."

Esse autoritarismo foi a principal causa da Revolução de 1932.

Reconstitucionalizado o País, em 1934, a Lei Magna, então editada, teve duração efêmera. Com o golpe de Estado de 1937, outorgou-se à Nação Carta Constitucional de feitio nitidamente corporativista.

$\mathrm{Na}$ área social, os principais efeitos de sua implantação foram os seguintes: 1. organização sindical baseada no critério da unidade; 2 . sistema confederativo rígido, que em estrutura piramidal, deveria funcionar como correia de transmissão para cumprimento das diretrizes do Chefe do Governo e sua promoção pessoal; 3. imposto sindical destinado a manter a fidelidade das cúpulas sindicais e que provocou a disseminação de sindicatos fantasmas, de cofres cheios e assembléias vazias; 4 . edificação de aparato legislativo de caráter paternalista, em detrimento dos procedimentos de autocomposição; 5. criação da Justiça do Trabalho de composição paritária e dotada de poder normativo.

Apesar da redemocratização do País, após o término da Segunda Grande Guerra, na Constituição de 1946 e nas subseqüentes, inclusive na atual, por obra de intenso lobby, a referida tralha corporativista foi mantida.

Agora, com a eleição do novo presidente da República, Fernando Henrique Cardoso, as esperanças são no sentido de que o referido modelo, apanágio de odiosos privilégios, deixe afinal de prevalecer, abraçando-se o modelo da liberdade sindical e da contratação coletiva.

Se Washington Luís estivesse vivo, certo de que não deixaria de aplaudir essa restauração de valores genuinamente democráticos. 